\title{
La reutilización del patrimonio construido, nuevos usos, buenas prácticas
}

\author{
Francisco Javier Soria López | División de Ciencias y Artes para el Diseño, \\ Universidad Autónoma Metropolitana (México) \\ URL de la contribución <www.iaph.es/revistaph/index.php/revistaph/article/view/4958>
}

\section{RESUMEN}

La reutilización del patrimonio edificado es una práctica de carácter histórico que ha permitido conservar inmuebles de todas las épocas a través del cambio de uso para adaptarse a nuevas necesidades de sus habitantes, trayendo al presente configuraciones arquitectónicas que reúnen valores aportados a lo largo de su existencia.

Se trata de una actividad arquitectónica que hoy día está tomando gran relevancia como un proceso de diseño sostenible pues atiende a los tres pilares esenciales, es decir, renueva el uso social de un espacio preexistente valioso, extiende la vida económica de la construcción y contribuye a disminuir el impacto ambiental que implica demoler y construir nuevamente.

La práctica de la reutilización de la preexistencia construida abarca una amplia gama de posibilidades de intervención, desde la restauración de inmuebles monumentales, la rehabilitación de edificios de valor cultural, la reconversión energética de inmuebles históricos y por supuesto la remodelación del parque edificado, opciones directamente relacionadas con sus condiciones patrimoniales.

\section{Palabras clave}

Arquitectura | Bienes inmuebles | Construcción | Diseño | Edificación | Edificios | Intervención | Reconversión energética | Rehabilitación | Reutilización | Sostenibilidad | 


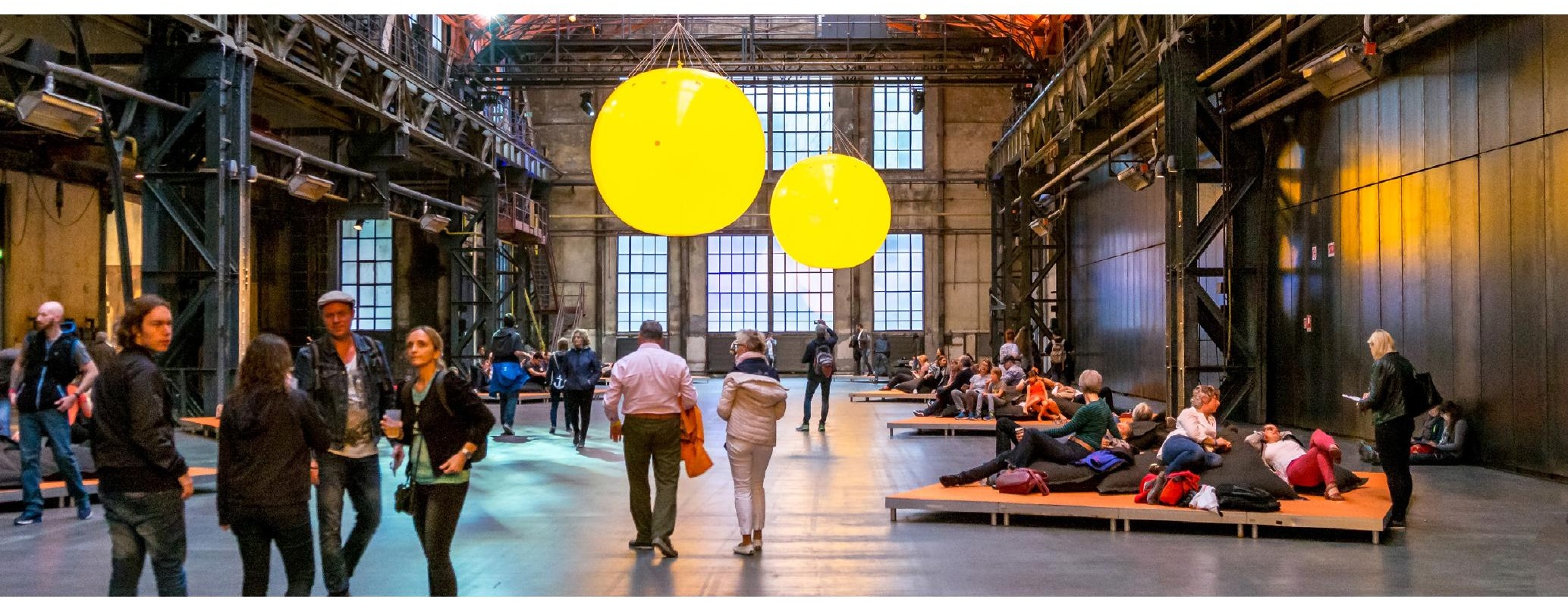

Adaptive Reuse of built heritage, new functions, good practices

\section{ABSTRACT}

The reuse of built heritage is a historical practice that has allowed the preservation of buildings of all ages by changing their function to adapt to new needs of society, bringing to the present architectural configurations that have gathered diverse values throughout time.

It is an architectural activity that today is taking on great relevance and recognition as a sustainable design process because it attends to the three essential principals, that is, it renews the social use of a valuable preexisting space, it extends the economic life of the construction and contributes to reduce the environmental impact of demolishing and building new again.

The procedure of reusing preexisting constructions enables a wide range of possibilities for intervention, including the restoration of monumental buildings, the rehabilitation of structures of cultural value, the energetic enhancement of historic properties and of course the remodeling of built spaces in general, options directly related to their heritage conditions.

\section{Key words}

Adaptive reuse | Built heritage | Sustainable design | Intervention | Sustainable rehabilitation | Energetic enhancement Historic properties |

Cómo citar: Soria López, F.J. (2021) La reutilización del patrimonio construido, nuevos usos, buenas prácticas. Revista PH, n. ${ }^{0} 104,2021$, pp. 144-162 $<$ www.iaph.es/revistaph/index.php/revistaph/article/view/4958> DOI 10.33349/2021.104.4958

Enviado: 29/05/2021 | Aceptado: 14/07/2021 | Publicado: 01/10/2021 


\section{INTRODUCCIÓN}

La conservación del patrimonio edificado, al igual que muchas otras disciplinas, ha sido alcanzada por el paradigma de la sostenibilidad, un contexto donde la relación hombre-naturaleza nos ha obligado repensar todo de nuevo; desde la esfera de lo social, hasta los aspectos ambientales y, por supuesto, los procesos económicos que esa interacción requiere para mantener su viabilidad en el tiempo y en el espacio.

Cada vez más está presente la necesidad de conservar el patrimonio cultural y natural heredado de generaciones pasadas. Se trata de un tema recurrente en la política, el arte, la literatura, la educación, la ciencia, el diseño... en fin, en prácticamente todas las acciones y actividades de la sociedad. Se trata de una inquietud que ha llegado a nuestros días, instalada como un compromiso ineludible, ya que "...la posesión, la creación y el cuidado del patrimonio constituyen, en cierto sentido, una necesidad social básica. La necesidad de recordar, de reinterpretar el pasado de manera individual y colectiva, y de servirse a tal efecto de la cultura material (entre otros medios) constituye un fenómeno social integrado en la propia estructura de la modernidad" (Mason y Torre 2001, 167).

Estamos actualmente en una encrucijada importante, pues mientras que en épocas pasadas el desarrollo y evolución social, económico, tecnológico y cultural se daba en espacios de tiempo muy extendidos, en ocasiones hasta de siglos de duración, a partir de la revolución industrial y, sobre todo, durante buena parte del siglo XX y lo que va del presente, la capacidad y velocidad de innovación, transformación, pero también de destrucción que ha adquirido la humanidad se ha acelerado de manera exponencial, lo que impone a nuestra generación la responsabilidad de garantizar la preservación de la cultura y la naturaleza al menos en las condiciones en que las hemos podido conocer y disfrutar hoy día.

Por ello, abordar la reutilización del entorno construido en el marco del desarrollo sostenible empieza por reconocer el camino en paralelo que han recorrido la conservación del denominado patrimonio cultural y la preservación del medio ambiente natural (Soria y García 2017). Se trata de dos caras de una misma moneda, que parten de una inicial visión que privilegia lo excepcional y que intenta proteger y hacer permanecer aquello que se considera como lo más valioso, único o representativo, pero que, con el tiempo, se cayó en cuenta de que los denominados monumentos o las grandes reservas naturales no se pueden aislar, sino que forman parte de contextos más amplios, complejos e interrelacionados que deben respetar todos sus elementos si hemos de conseguir mejores condiciones de conservación.

Esto define en buena medida la sostenibilidad, esa visión integral que reconoce que la acción social derivada del espíritu humano se da en un lugar 


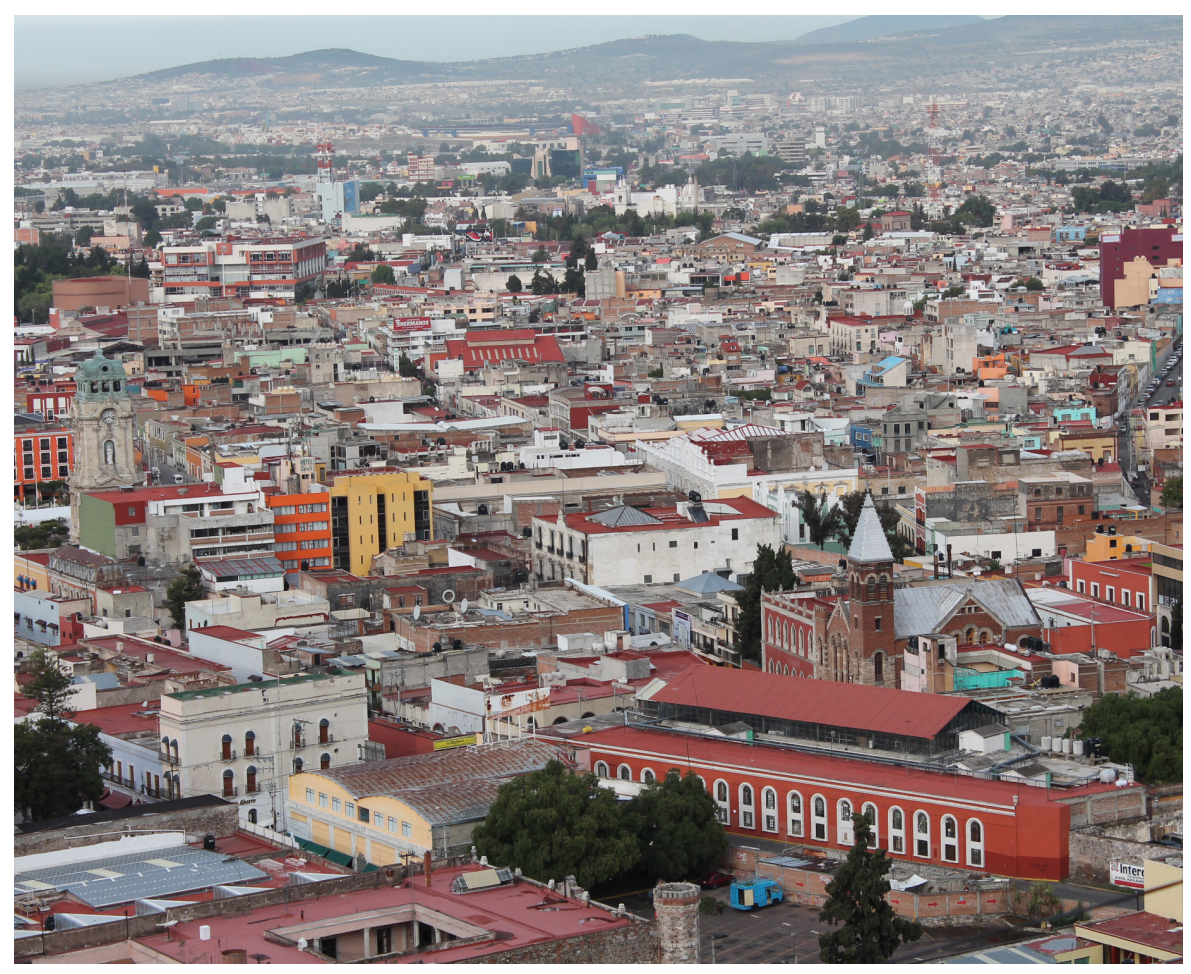

determinado, que se transforma y ocupa a lo largo del tiempo como espacio de vida adaptado para el desarrollo y bienestar de un grupo social especifico. Entender esta relación y la necesidad de mantener un enfoque holístico que debe visualizar todas las aristas del problema resulta indispensable, lo que implica entonces abordar los tres ${ }^{1}$ aspectos que caracterizan el denominado desarrollo sostenible:

1. El pilar social. Constituye la puerta de entrada al tema de la sostenibilidad, pues los seres humanos, organizados socialmente, llevan a cabo su vida encaminada "idealmente" a conseguir un bienestar físico y sicológico. Existe, desde luego, el deseo de llegar a tener una cierta calidad de vida, al satisfacer aspiraciones que el entorno cultural y natural condicionan a cada grupo social.

En ese sentido la Agenda 2030 para el desarrollo sostenible reconoce entre sus objetivos "...la necesidad de construir sociedades pacíficas, justas e inclusivas que proporcionen igualdad de acceso a la justicia y se basen en el respeto de los derechos humanos..." (Naciones Unidas 2015, 11). Desafortunadamente, la sociedad contemporánea está lejos de ese ideal de equilibrio, de vida donde habría igualdad de oportunidades, de justicia, de acceso a la educación. Hoy día la brecha entre países desarrollados y aquellos en vías de obtenerlo, se hace cada vez más grande.
El entorno construido desempeña un papel primordial en el desarrollo sostenible, ya que la ocupación del territorio, la expansión urbana y la edificación de nuevas arquitecturas impactan de una manera importante a la naturaleza, acción que se ha acelerado de manera exponencial desde mediados del siglo XX, como ocurre en la ciudad mexicana de Pachuca | foto Francisco J. Soria

Conviene remarcar que los tres pilares de la sostenibilidad implican la síntesis de una realidad mucho más compleja e interrelacionada; lo social abarca asuntos relativos a la cultura, a los derechos humanos, la pobreza, la educación, la salud entre muchos otros; la economía deriva en problemáticas de empleo, intercambio comercial, innovación tecnológica, producción, explotación de los recursos naturales y humanos; lo ambiental se refiere a la naturaleza y sus procesos, los océanos, el cambio climático, la perdida de especies, la contaminación ambiental por mencionar solo algunos. La ONU ha definido 17 objetivos del desarrollo sostenible y 169 metas específicas que detallan esta compleja y diversa realidad que enfrenta la humanidad. 
2. El pilar ambiental. La acción humana sobre el entorno natural, necesaria para la supervivencia, ha representado, simultáneamente, la transformación y destrucción progresiva de la naturaleza. Se tiene en ocasiones la falsa creencia que todas las sociedades pasadas vivían en armonía con su entorno. Realmente, en distintos momentos de la historia, en diferentes territorios, ha habido grandes crisis ambientales (casi siempre de la mano de crisis social y económica de esos mismos grupos humanos). En todo caso la gran diferencia de dichas contingencias ecológicas (sociales y económicas) se situaba en la escala; es decir que el impacto se daba en una zona muy definida del planeta y más allá, había otra fauna por cazar, madera por cortar, territorio por ocupar. La crisis ambiental parece que hoy día llega a un límite global donde los bienes naturales están comprometidos: ya no hay donde respirar aire limpio, agua potable suficiente, tierra fértil para el cultivo, ante la casi total apropiación que se ha hecho de la naturaleza. Transitar hacia un desarrollo sostenible pasa por entender que el sistema natural en el que vivimos es, en sus condiciones actuales, un sistema cerrado, que tiene unos límites y un funcionamiento específico que debemos no solo identificar y conocer, sino respetar si hemos de encontrar y recuperar el equilibrio necesario para una vida con bienestar. La aspiración principal se centra en “...preservar y utilizar sosteniblemente los océanos y los mares, los recursos de agua dulce y los bosques, las montañas y las zonas áridas, y a proteger la diversidad biológica, los ecosistemas y la flora y fauna silvestres" (Naciones Unidad 2015, 10), una carrera contra el tiempo que por ahora parece perderse.

3. El pilar económico. La actividad económica supone un factor ineludible si se ha de transitar hacia una actitud sostenible ya que resulta cada vez más difícil generar las condiciones para una vida de bienestar. Sostener un país, un estado o una ciudad mediana, incluso el más pequeño asentamiento humano, requiere actividades productivas que permitan generar la riqueza apropiada para satisfacer las necesidades básicas de su población, que van desde los aspectos físicos y biológicos (comida, agua potable y cobijo), hasta las necesidades socioculturales (educación, recreación, creencias, ritos o actividades tradicionales), que forman parte del entorno de vida social. Por ello, transitar hacia un "crecimiento económico sostenido, inclusivo y sostenible es esencial para lograr la prosperidad, lo que solo será posible si se comparte la riqueza y se combate la desigualdad de los ingresos" (Naciones Unidas 2015, 9).

En este orden de ideas, el entorno construido desempeña un papel primordial en la sostenibilidad, ya que la ocupación del territorio, la expansión urbana y la edificación de nuevas arquitecturas impactan de una manera importante en la naturaleza. Hoy en día, a raíz de la crisis ambiental y la cada vez más apremiante necesidad de aprovechar racionalmente los recursos, se está en la obligación de comprender que el medio construido debe obedecer a nue- 
vas lógicas: menor impacto, más equilibrio y mayor compatibilidad con el ambiente natural y cultural, donde el respetar, reciclar, rehabilitar y reutilizar forman parte de ese cambio necesario. En este sentido, la reutilización del patrimonio edificado gana terreno como una acción eminentemente sostenible, que inicia sus procesos desde el reconocimiento y valoración de la arquitectura preexistente; que aporta al conservar espacios de vida socialmente significativos; que disminuye la carga sobre el entorno natural y se integra a los ciclos económicos actuales al albergar nuevas funciones útiles para la sociedad contemporánea.

\section{NUEVOS USOS EN EDIFICIOS EXISTENTES: UNA PRÁCTICA HISTÓRICA SOSTENIDA}

La concepción y edificación de los espacios que habitamos implica un proceso que siempre ha estado presente en todas las sociedades. Se trata, de hecho, de una práctica histórica que permitió la aparición de los asentamientos humanos, desde los más incipientes que caracterizaron a los grupos nómadas, hasta llegar a las megalópolis actuales. Este paso y permanencia del hombre por el territorio ha dejado, como una de sus huellas más profundas, el entorno construido, con ciudades, arquitecturas e infraestructuras que, con el transcurso del tiempo, han constituido un enorme y diverso patrimonio edificado.

La evolución de la arquitectura se ha dado a partir de algún tipo de preexistencia edificada, bien como referencia para idear un nuevo espacio o, como se ha dado de manera extensa, para utilizar construcciones ya existentes para albergar una función nueva, renovar el uso ya dado o simplemente extender su existencia física. Pero se trata de una permanencia dinámica, estrechamente vinculada a la intencionalidad de conservar aquello que se considera valioso, importante o simplemente útil; algo que pensamos que no puede perderse o desaparecer, al menos no del todo.

La conservación de elementos materiales significativos no se centra solamente en su existencia física sino sobre todo en aquello que representan para un determinado grupo social; no basta, entonces, conservar el bien sino también su significado. Se puede decir que la "valorización es la llave de acceso del dispositivo" (Choay 2007, 197) cuando nos referimos al tema de la conservación y reutilización del patrimonio edificado. Estos procesos de valoración que hace la sociedad no se mantienen estáticos o permanentes; por el contrario, se muestran versátiles, relativos a tiempo y lugar, mediado por lo subjetivo y por lo mismo producto de una construcción social: todo patrimonio tiene un valor, porque éste es condición necesaria para aquél: "un bien patrimonial no es valioso por ser patrimonial, sino que es patrimonial porque es valioso" (Barreiro 2013, 36). 

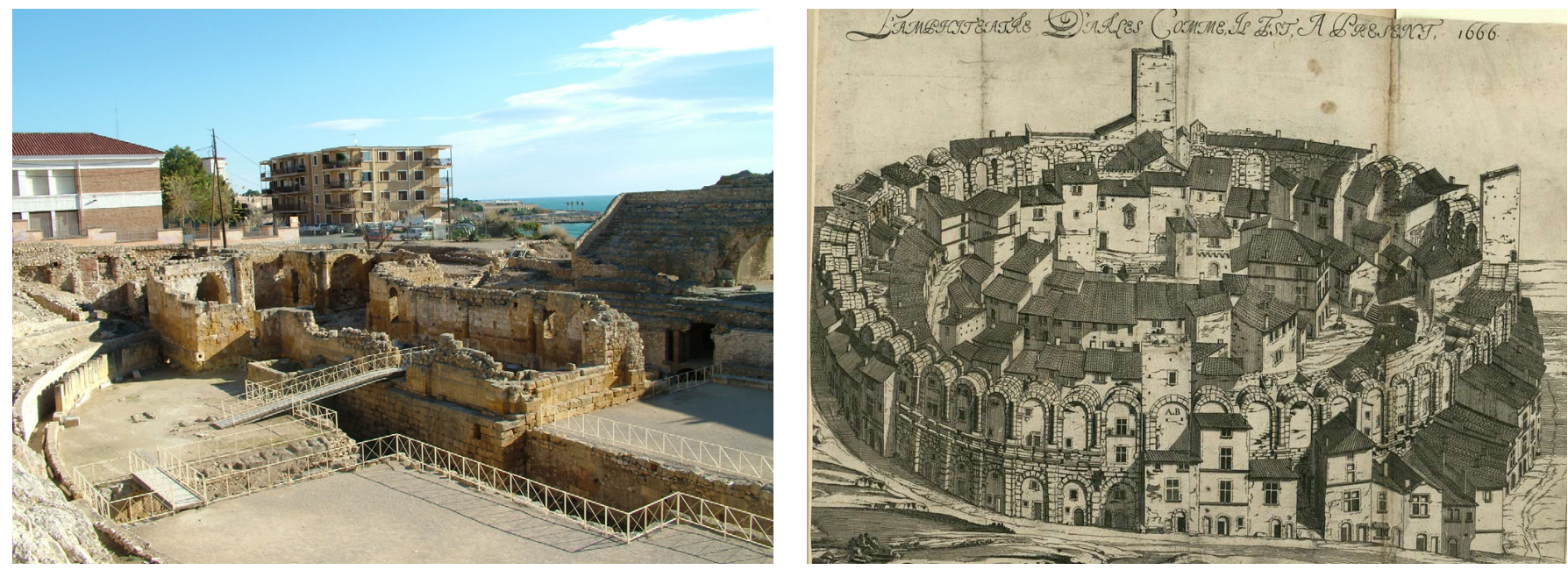

La reutilización y ocupación de espacios arquitectónicos preexistentes es un proceso que siempre ha estado presente en todas las sociedades. De hecho, esta práctica histórica permitió, con el transcurso del tiempo, configurar un enorme y diverso patrimonio edificado. A la izquierda, antigua edificación romana en Tarragona (España), ocupada posteriormente por un templo cristiano y hoy día, un sitio arqueológico de alto valor cultural | foto Francisco J. Soria

La obsolescencia de la arquitectura prevaleció en épocas pasadas ligada a procesos sociales que derivaron en formas de reutilizar edificaciones de todo tipo, incluso, como en el caso de Arlés (Francia), la posibilidad de generar una pequeña población dentro de un anfiteatro romano. En el siglo XVII, el arquitecto y artista Jacques Peytret, realizó esta extraordinaria imagen (a la derecha) que documenta este sitio histórico | fuente

PICRYLThe World's Largest Public Domain Media Source
En el ámbito del entorno construido los procesos de su reutilización han estado siempre presentes, aunque las razones para conservarlos mediante la extensión de su permanencia física han variado a lo largo de los siglos. Las motivaciones tocan distintas esferas, que, sin pretender abarcar la totalidad de las opciones, podemos ubicar como aquellas de orden material-tecnológico, simbólico-representativo, histórico-estético, funcional-económico y, de acuñación más reciente, social-ambiental.

A partir de lo anterior, se puede hablar de procesos de identificación y apreciación de lo edificado que permiten, mediante el conocimiento del contexto donde se encuentra, la temporalidad de su reconocimiento, el uso que se incorpora y la intencionalidad que hay detrás; entender la reutilización arquitectónica como una forma de valoración del patrimonio edificado.

Mucho se ha debatido sobre la intervención en lo ya construido, en el espacio arquitectónico preexistente, como una práctica histórica que la mayoría de las veces obedecía a motivaciones más de orden pragmático e ideológico que a una intención de conservar el patrimonio con fines de transmisión hacia el futuro. "Antes del siglo XIX la práctica arquitectónica confiaba en sus propios valores sincrónicos (...) El devenir histórico se manifestaba mediante la caducidad de los objetos. Lo viejo, como tal, no era motivo de valoración artística o arquitectónica..." (Gracia 2001, 59).

En épocas pasadas constituía una práctica poco cuestionada la desaparición por completo de edificios centenarios para edificar una arquitectura contemporánea de ese momento histórico; pero también se ha practicado en las ciudades hasta nuestros días la conservación y aprovechamiento de inmuebles construidos. La reutilización de la arquitectura se da justamente porque se le asigna algún tipo de valor, aunque estas razones no siempre bordaran 
la tradición histórico-estético de la visión patrimonialista forjada en los siglos XIX y XX.

En ese sentido la obsolescencia de la arquitectura preponderaba en épocas pasadas. Las grandes infraestructuras concebidas y edificadas por imperios que se pensaban eternos, pero que el tiempo terminó por dominar, se convirtieron en posibilidades de uso y re-uso de la preexistencia.

Se puede citar, como ejemplo de esta dinámica, el caso del antiguo anfiteatro romano de Arlés (Francia), el cual se reutilizó en época medieval para uso habitacional. Llegó a albergar en su interior un barrio entero, con más de doscientas casas e incluso dos iglesias (Directión du Patrimoine 2002), que transformaron el lugar, pero simultáneamente lo conservaron. Su proceso de reutilización obedeció seguramente a una valoración de sus virtudes arquitectónicas de orden espacial y estructural que ofrecían, en su forma y materialidad, seguridad y cobijo para los entonces nuevos pobladores del inmueble.

Tiempo después, dado el carácter dinámico y socialmente dirigido de los procesos de valoración, en el siglo XIX la ruina romana fue liberada de las construcciones adosadas, aplicando criterios monumentalistas de conservación, para restaurarse y convertirse en un atractivo para la contemplación. En años más recientes se ha vuelto a utilizar como centro de espectáculos.

La ideología actúa, también, como un potente motor para reconfigurar sitios altamente representativos para una sociedad determinada, resignificando el lugar para cumplir nuevas necesidades sociales. En ocasiones la intervención puede resultar más violenta, en busca de un cambio evidente, sin embargo, el proceso de valoración de la preexistencia impide a propios y extraños hacer desaparecer lo anterior y se optan, mediante la reutilización como proyecto de arquitectura, no solo resignificar el lugar, incluso renovar su función a condiciones nuevas. La mezquita de Córdoba es un ejemplo de enorme sensibilidad hacia un lugar de culto, que mantiene esa misma función, pero para una fe distinta. La simbiosis resulta increíble y las estructuras parecen fundirse, lo que constata el análisis como composición arquitectónica que hace A. Capitel $(2001,53)$ de este edificio: "Convertir la mezquita en catedral supuso entender la compleja estructura de su forma (...) analizando el modo en que era necesario someterse a ella, por un lado, y corregir su irresuelta ambigüedad espacial, por otro. La idea de salvaguardar lo antiguo sin renunciar a su transformación preside la operación arquitectónica (...) La transformación aparece, no como obligada, pero si como lógica secuela de nuevas necesidades e interpretaciones en dialéctica con la naturaleza compositiva de la arquitectura originaria".

La arquitectura tiene, como una de sus premisas fundamentales, la utilidad como espacio para habitarse, diseñada para funcionar de determinada 


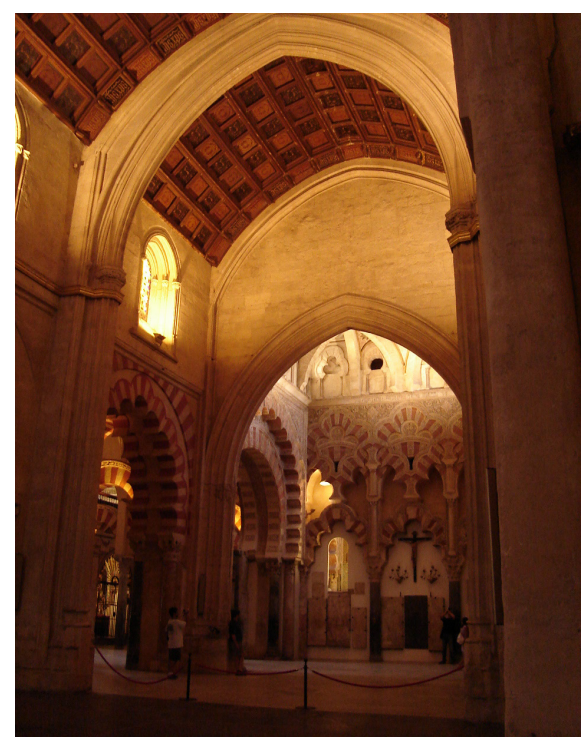

La mezquita de Córdoba constituye un ejemplo de enorme sensibilidad hacia un lugar de culto. Mantuvo su función original, pero para una fe distinta, lo que implicó un enorme desafío de conservación y transformación para lograr un equilibrio arquitectónico y funcional admirables | foto L. F. Guerrero
2.

Sin duda alguna la época pospandemia de la COVID-19 pondrá a debate nuevas formas posibles de uso de inmuebles de todo tipo desde oficinas corporativas, inmuebles comerciales y recintos escolares, hasta la misma vivienda que, como se ha experimentado en este último año y medio, deberán adaptarse a condiciones nuevas de organización y uso social de los espacios habitables a partir del impacto que el virus SARS-CoV-2 generó en el mundo entero. manera, sin renunciar a su capacidad de expresión estética. Sin embargo, el valor de uso es el elemento que articula el espacio con el sujeto quien, al habitar el lugar, le proporciona su sentido como arquitectura. La re-funcionalización del espacio patrimonial ha sido una práctica común, que surge también a partir de múltiples factores, incluso los de orden económico. La reutilización de edificaciones en distritos industriales o comerciales como viviendas y talleres para artistas en grandes ciudades como Nueva York, hacia los años 60 del siglo pasado, aparece como una alternativa barata, al ocupar espacios degradados, obsoletos y de alguna manera despreciados. Hoy día, más de medio siglo después, en cada vez más ciudades estos distritos se han revalorizado económicamente, en buena medida por el éxito de la reutilización de dichos espacios, y han incorporado nuevos usos a sectores urbanos enteros. Esta tendencia, que se mantiene en el mercado inmobiliario actual, también tiene sus efectos negativos como el de la gentrificación.

En las últimas décadas otras motivaciones han surgido para justificar la importancia de reutilizar edificaciones con valor patrimonial y tiene que ver con su valor ambiental, con la posibilidad de contribuir a reducir el impacto ambiental al extender su ciclo de vida. Un argumento reiterado reza que "el edificio más verde es el que ya está construido" (Elefante 2007, 26), pues ya aportó su cuota de gasto energético, extracción y transformación de materia prima. Aunque dicha afirmación deba matizarse, pues no se trata de una verdad absoluta, ciertamente la extensión de la vida útil de una edificación contribuye a disminuir el impacto que implica la demolición y construcción nueva.

En este contexto, el proyecto de Emscher Park en Alemania constituye probablemente uno de los casos de mayor éxito en la reutilización enfocada al valor ambiental. Se trata de una intervención sobre un territorio de más de $450 \mathrm{~km}^{2}$, a lo largo de poco más de $85 \mathrm{~km}$, que se extiende desde el río Rin, cerca de Duisburg, hasta Bönen, para reconvertir la antigua industria siderúrgica de la región del Ruhr en un enorme parque de corte socioambiental (Metropoleruhr 2013,3). No solo se cambió la imagen de una industria que degradaba el entorno al convertirse ahora en soporte físico de un parque ecológico, sino que también se combinó para albergar espacios de uso colectivo para diversas actividades sociales, culturales y recreativas, como puede apreciarse en Duisburg Nord, uno de los sitios emblemáticos de este parque regional (Soria 2006, 113-131).

El cambio de uso en edificaciones preexistentes está ganando reconocimiento social y profesional ${ }^{2}$ como una práctica contemporánea necesaria por motivaciones de orden cultural, ambiental, social y económico. Recientemente el premio Pritzker de arquitectura fue otorgado a los arquitectos A. Lacaton y J. PH. Vassal, que sostienen que "La transformación es la oportunidad de hacer más y mejor con lo que ya existe. El derribo es una 


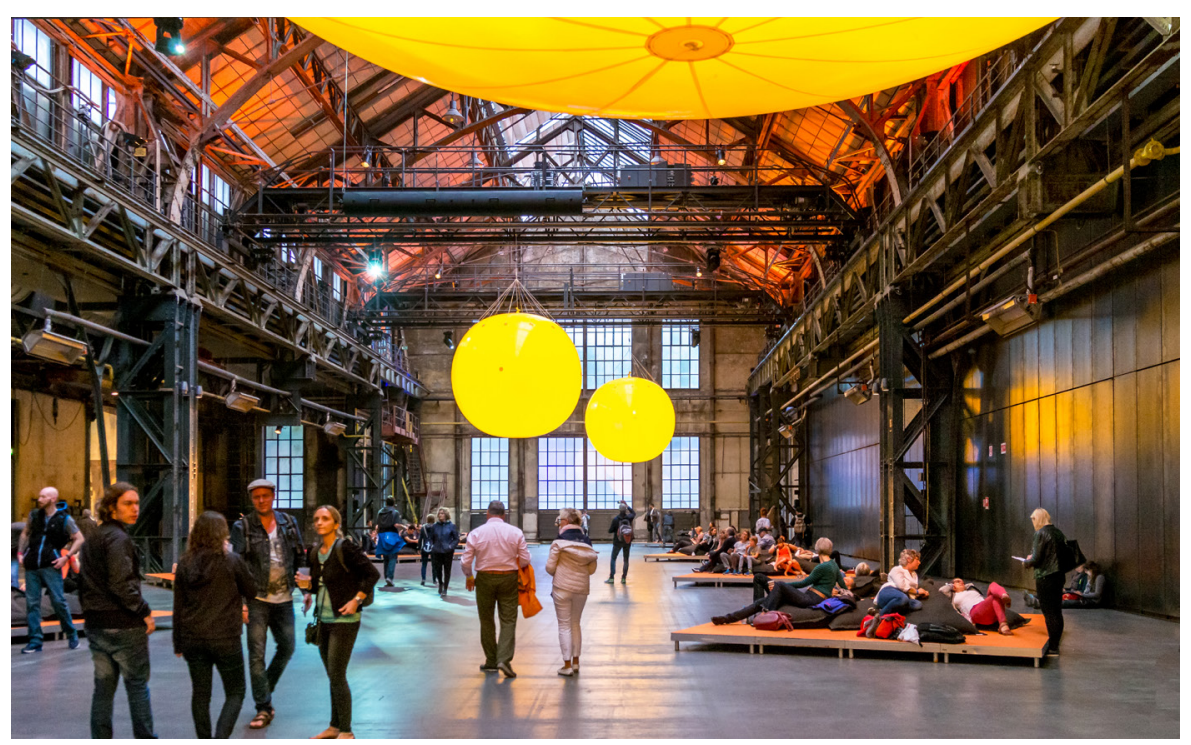

decisión fácil y de corto plazo. Es una pérdida de muchas cosas: desperdicio de energía, desperdicio de material y desperdicio de historia. Además del impacto social muy negativo" (Olivares 2021). Se trata de una postura que defiende la necesidad de conservar la preexistencia, sobre todo de espacios de construcción reciente, los cuales se convierten en lugares que impactan positivamente en la vida de sus habitantes al considerar la reutilización como un mecanismo mediante el cual se conjugan las variables de carácter económico y social (Mayorga y Soria 2014, 222).

Esto viene a confirmar que los distintos tipos de asentamientos humanos que se han desarrollado a lo largo de la historia representan el mejor testimonio de que la práctica de la reutilización del patrimonio edificado ha sido una constante. La premisa de dotar de nuevos usos a edificios existentes ha evolucionado desde épocas lejanas hasta las décadas más recientes, para convertirse, hoy día, en una acción consciente y premeditada que se orienta a conservar, resaltar y aportar valores a la preexistencia, precisamente por su condición como patrimonio.

\section{BUENAS PRÁCTICAS PARA UNA INTERVENCIÓN SUSTENTABLE EN EL PATRIMONIO EDIFICADO}

El espacio arquitectónico preexistente tiene diversas formas y tipologías que deben considerarse al abordar su intervención: desde las construcciones monumentales con reconocimiento social por su permanencia en el tiempo o la importancia de su significación, hasta edificaciones de carácter modesto desde el punto de vista estético o histórico, que forman parte cotidiana del
Las antiguas industrias siderúrgicas alemanas representaron obsolescencia y depredación del entorno natural para la sociedad hacia finales del siglo XX. La reutilización de esta infraestructura a escala regional se convirtió en un aliado para la recuperación de áreas verdes para la recreación de los habitantes. El espacio Jahrhunderthalle Bochum, en la antigua planta industrial de gas de Bochumer Verein, se ha convertido en un espacio para la cultura, los negocios y el entretenimiento | foto Michael Becker 
lugar y que pasan muchas veces desapercibidas. El elemento común a todos estos inmuebles es su uso; concretamente el proyecto de arquitectura que permite desarrollar una propuesta para que ese espacio o lugar resulte habitable de acuerdo con una nueva función.

Como se describió anteriormente, el proceso de valoración de la preexistencia edificada define su condición patrimonial. De igual manera el proceso de intervención de un inmueble o entorno construido pasa por la intencionalidad del proyecto de uso. Cada lugar tiene su especificidad y, por lo tanto, los elementos de valor que se han de conservar, así como el grado de transformación que las aportaciones para el nuevo uso y, consecuencia de ello, la nueva función, espacialidad y habitabilidad, han impreso sobre el inmueble.

No se pretende ubicar a la reutilización como el concepto dominante de la conservación del patrimonio edificado, puesto que cada campo -conservación, restauración, rehabilitación o la remodelación de arquitectura tienen sus propios ámbitos de competencia-, pero resulta evidente que conforma el elemento transversal en la ecuación, ese común denominador siempre presente, que se materializa en el proyecto de diseño que utiliza un espacio arquitectónico preexistente previamente valorado.

En este contexto de la sostenibilidad, las prácticas de la reutilización del patrimonio edificado se han ido definiendo y haciendo más evidente su diversidad y amplitud. Todas se encaminan a mejorar las condiciones de vida que la sociedad, en general, y de las personas, en particular, a través de la conservación y puesta en valor de los espacios preexistentes en función de criterios de orden social, cultural, económico y, por supuesto, ambiental. Esta abundancia de posibilidades de reutilización arquitectónica deriva justamente en formas distintas de intervenir en estos espacios:

\section{El uso y destino de lo monumental}

La noción de restaurar un edificio o un conjunto urbano está, en la actualidad, claramente identificada con la intervención de un patrimonio inmueble que destaca por su valor cultural; los aspectos históricos, estéticos, simbólicos, compositivos o materiales representativos de una época pasada deben conservarse con la mayor autenticidad posible. La restauración en el campo arquitectónico está dirigida a intervenir físicamente en un inmueble con valor cultural con el fin de garantizar su permanencia y con la finalidad de "la restitución o la mejora de su comprensión y el restablecimiento de su unidad potencial, que ha sido deteriorada o perdida por un proceso de degradación, y para que el edificio siga existiendo como objeto capaz de provocar una experiencia estética" (Martínez 2012, 25). Resulta fundamental que estas operaciones se realicen sin incurrir en alteraciones o falsificaciones de su naturaleza documental. 


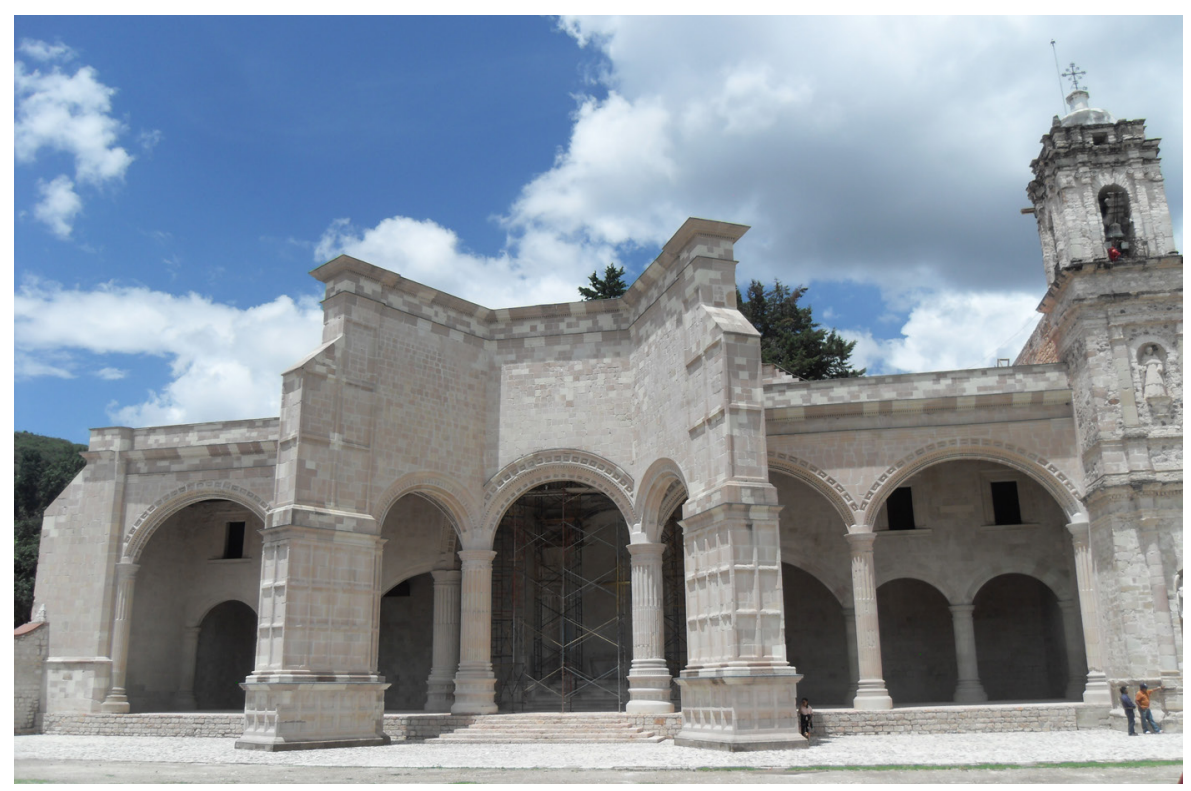

Al mismo tiempo, los diferentes documentos internacionales recomiendan siempre dedicar los edificios restaurados y conservados "a una función útil a la sociedad", pero sin perder de vista que "tal dedicación es por supuesto deseable pero no puede alterar la ordenación o decoración de los edificios" (ICOMOS 1964). El uso se hace necesario para garantizar su conservación sobre todo a largo plazo. Esto último resulta especialmente importante para el patrimonio más "modesto" el cual todavía enfrenta mayores dificultades para su valoración en relación con los grandes conjuntos y edificios de escala monumental.

El proyecto de uso, en el contexto de una restauración, debe entonces cuidar los aspectos de autenticidad e integridad del bien inmueble que se interviene, sin renunciar a incorporar elementos que garanticen su funcionamiento, seguridad y accesibilidad, siempre priorizando la compatibilidad e, igualmente, la adaptabilidad y respeto máximos hacia la preexistencia.

En ese sentido, la visión desde la reutilización puede aportar a la restauración más tradicional en su camino hacia la sostenibilidad. Mucho se ha debatido en torno a la conveniencia de reproducir, a imagen y semejanza, un inmueble de épocas pasadas cuyas fuentes o bancos de materiales ya no se encuentran disponibles ante la crisis ambiental actual. ¿Es válido restaurar un techo de vigas con árboles con siglos de existencia, abundantes en su época, pero escasos hoy día y, por lo tanto, bienes naturales dignos de conservación en sí mismos? De forma idéntica se puede decir de canteras agotadas o del uso de materiales que comprometen la salud y que hoy día ya no están permitidos.
La restauración y uso de edificaciones de carácter monumental deben considerar su viabilidad en el largo plazo, que garantice su conservación y valoración en el tiempo. El uso y rescate de técnicas y materiales tradicionales se enfrenta a cuestionamientos sobre la explotación de recursos hoy día escasos y que ponen a debate los criterios de intervención. La extraordinaria capilla abierta del siglo XVI en Teposcolula (Oaxaca, México) fue reconstruida a "imagen y semejanza" requiriendo enormes cantidades de piedra, madera y cal | foto Francisco J. Soria 
El caso de la restauración de la techumbre de Notre Dame en París abrió un debate interesante, puesto que se acudió a bosques centenarios, que aportarán los 1000 árboles necesarios para reestablecer la estructura. Esta decisión ha sido calificada por algunas voces críticas al proyecto como obsoleta y cuestionable, porque el gobierno optó “...por este dúo infernal de madera y plomo, que hizo posible el fuego y la contaminación por el plomo" (Louis 2021 , 4). El proyecto de intervención deberá incorporar, necesariamente, elementos materiales y técnicos contemporáneos que contribuyan a mejorar, entre otros aspectos, la seguridad del inmueble histórico.

La aportación del enfoque de la reutilización, de adecuar los edificios a ciertas condiciones y funciones actuales insoslayables, de manera selectiva y cuidadosa, puede contribuir a ampliar la visión de las intervenciones en inmuebles de valor cultural, que tenga también en cuenta una mirada sostenible.

\section{La rehabilitación del patrimonio edificado}

Las nociones de rehabilitación o habilitación de un objeto a su antiguo estado, largamente utilizadas en el campo de la conservación y restauración del patrimonio cultural, conllevan una idea más amplia, que supone una acción encaminada a "la recuperación de una actividad o función perdida o disminuida" (RAE 2001, 1932), que puede aplicarse a edificaciones de todas las épocas. Las posibilidades de la rehabilitación en el ámbito de la arquitectura pueden "equipararse al término 'reparación' por aplicarse a cualquier objeto, no solo a los objetos culturales (...) pero lleva implícita una fuerte componente funcional que permite establecer la equivalencia con el 'volver a poner en funcionamiento' o 'en eficiencia' (...), lo que llevaría a su aplicación especialmente en el campo de la arquitectura y el urbanismo" (DíazBerrio 2002, 44).

Persiste entonces de manera importante la idea de conservar las cualidades físicas y arquitectónicas principales -de ahí su afinidad con el ámbito de la conservación- pero, al mismo tiempo, implica acciones para mejorar las condiciones de uso, habitabilidad y seguridad, lo que representa la incorporación de elementos o cambios puntuales para adaptarlos a las nuevas funcionalidades. Este campo está dirigido en especial a un amplio espectro de inmuebles con valor histórico, arquitectónico y ambiental ubicado en zonas urbanas o rurales de valor patrimonial, que no entran en la clasificación de lo monumental pero cuya permanencia está unida indispensablemente a la preservación del entorno, la imagen y paisaje urbanos de dichos sitios.

La reutilización, en este rubro, implica un respeto importante a lo existente, a su carácter social, cultural e incluso formal y material, pero al mismo tiempo requiere de cambios o adiciones para su adecuado funcionamiento; "incluye simultáneamente la 'conservación' (...) y la 'transformación'(...) para dotarla 
[a un área urbana existente] de elementos adecuados a sus características arquitectónicas y para otorgarle mejores condiciones de habitabilidad y uso" (González-Varas 2003, 545). El proceso de diseño encaminado a rehabilitar un inmueble puede establecerse como un punto intermedio entre la restauración y la renovación, conserva las características físicas, materiales, funcionales y de apariencia principales, pero también transforma de manera selectiva.

\section{La reconversión energética de espacios preexistentes}

La crisis ambiental actual que ha generado la actividad humana para sostener sus formas de vida se ha convertido en un tema de gran importancia en el contexto mundial actual. Cómo se producen, operan e incluso desechan los entornos construidos, representa un gasto energético y consumo de recursos que requiere, cada día, mayor atención.

La reconversión en el ámbito de la conservación y reutilización arquitectónica dirige su objetivo principal a conseguir que el edificio preexistente tenga un mejor rendimiento y eficiencia desde el punto de vista energético. De esta manera reconvertir un inmueble implica, sobre todo, la incorporación de nuevas tecnologías y componentes para, a partir de mantener buena parte de su configuración preexistente, mejorar la pérdida o ganancia de temperaturas (aislamiento), incluir instalaciones eléctricas de bajo consumo energético, añadir aquellas que puedan producir energía propia, integrar sistemas de captación y ahorro de agua, entre otras infraestructuras posibles. El reto del
Los edificios patrimoniales se intervienen para mejorar su comportamiento energético, para lo que se incorporan elementos contemporáneos, en especial la envolvente de los edificios, que incluye fachadas y cubiertas. En la imagen de la izquierda una antigua capilla gótica en Girona que incorpora una techumbre metálica que contrasta con la solución tradicional de teja, pero que mejora su rendimiento ante factores climáticos

La rehabilitación de inmuebles de valor patrimonia tiene, desde el punto de vista de la sostenibilidad, el compromiso de conservar los valores de lo construido y, simultáneamente, incorporar elementos para adecuarse al nuevo uso. En la imagen de la derecha, los espejos de agua integrados a la antigua fábrica textil del siglo XIX, reutilizada como Centro de las Artes de San Agustín, en Oaxaca | fotos Francisco J. Soria
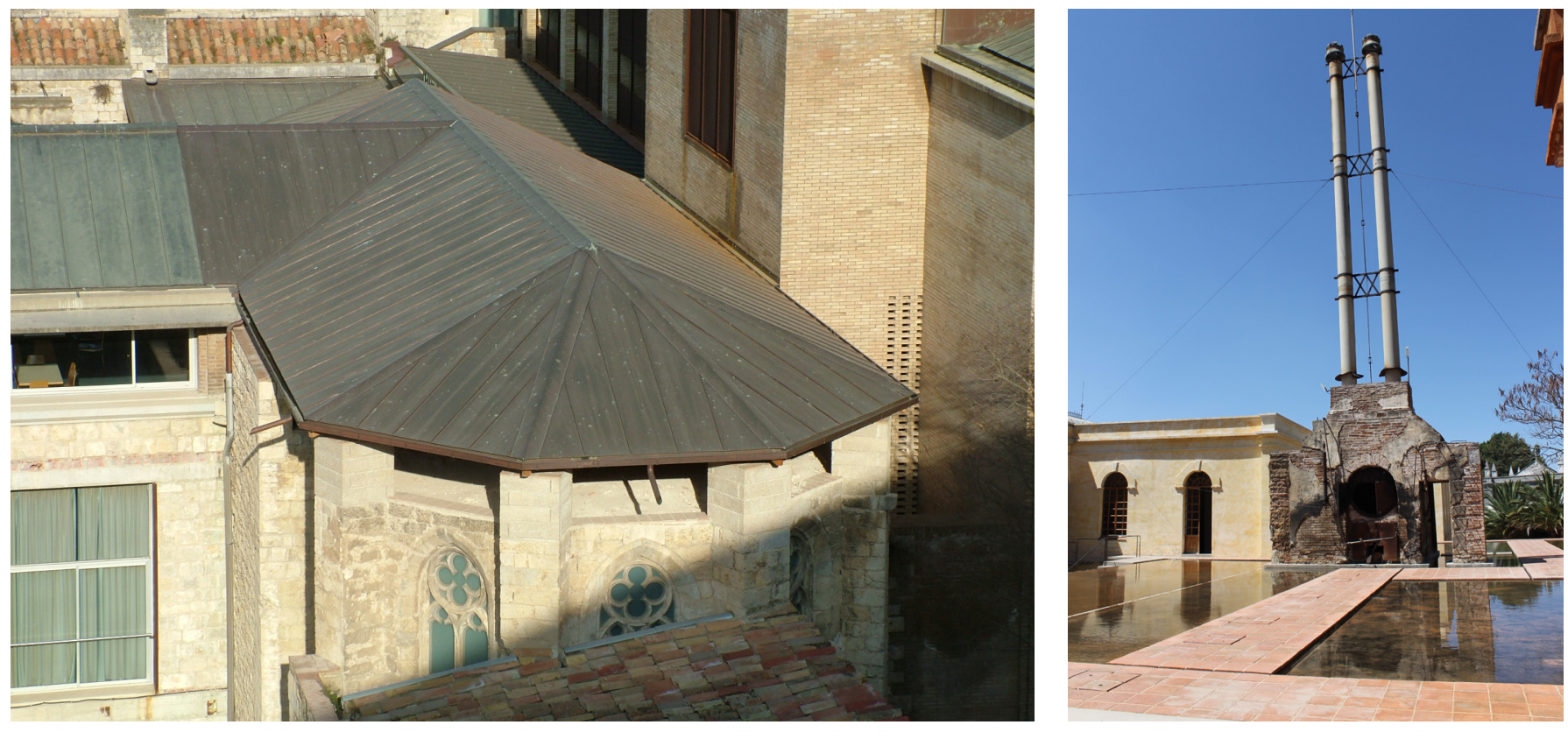
El enorme parque edificado construido a partir de la segunda mitad del siglo XX, que las instituciones especializadas no consideran inmuebles patrimoniales, está llegando al final de su vida útil. La renovación y remodelación de esta arquitectura puede contribuir a reducir el impacto ambiental al evitar construcciones nuevas y mantener una determinada imagen urbana de un sector de la ciudad, extendiendo su permanencia al ser reutilizados. Este edificio de departamentos de los años 60 del siglo pasado en Ciudad de México fue renovado en sus interiores y se le adicionó un nivel superior para extender su vida útil y mejorar las condiciones de habitabilidad y rentabilidad | foto Francisco J. Soria

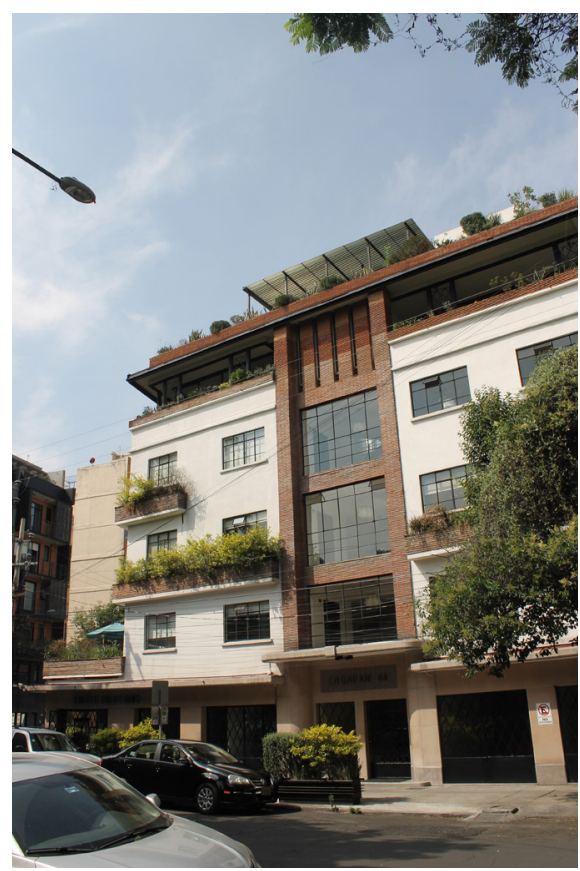

proyecto se centra en cómo integrar dichos componentes para que convivan con lo existente, pero no escatima en la sustitución de materiales o elementos "obsoletos" o en agregar lo necesario para llegar a la meta propuesta de alta eficiencia energética y re-funcionalización predeterminada. Buena parte de las acciones están encaminadas a la envolvente del edificio, fachadas, techumbres y vanos para garantizar un mejor rendimiento térmico global.

Se trata de un amplio campo de acción, que nuevamente debe incorporar el tema de la valoración, donde inmuebles de reconocida importancia cultural requieren un proceso diferente a inmuebles de valor ambiental o aquellos de orden utilitario donde las decisiones de cambios y transformaciones parecen más fáciles de tomar. Una intervención adecuada, "tiene como objetivos la mejora energética, el bajo impacto, la valoración histórica y la regeneración económica y social de las zonas urbanas. Esta nueva visión ha hecho más compleja la intervención, ya que requiere el respeto y la apreciación de las cualidades estéticas, materiales y espaciales, así como la compatibilidad y la reversibilidad de los trabajos" (Lucchi 2015, 230).

\section{La remodelación y renovación del parque edificado}

Los términos remodelar o renovar se refieren, desde el punto de vista arquitectónico, a la intervención de inmuebles que requieren acciones para modernizar o reformar su funcionamiento y apariencia. La remodelación busca intervenciones orientadas a los aspectos de carácter formal y técnico. Se encamina a mejorar o cambiar función y apariencia y, casi siempre, a sacar provecho del valor económico y de ubicación como superficie construida de un edificio determinado. Esto último se aplica, sobre todo, para espacios de carácter comercial o de oficinas que suelen cambiar de configuración en períodos relativamente cortos.

El concepto de renovación se asemeja a la idea de remodelar, ya que supone "hacer de nuevo" pero de mayor aplicación en la escala urbana y "alude a la obtención de una condición nueva (...) con una idea implícita de 'mejora' o 'actualización' que implica una ‘sustitución' de sus componentes materiales" (García-Varas 2003, 546). Se refiere sin duda a la intervención de espacios que están degradados, deteriorados o, en su caso, obsoletos y que requieren de un proceso de intervención para recuperarlos o actualizarlos a nuevas demandas de los usuarios.

Este tipo de intervención, si bien puede considerarse dentro del abanico que cubre la reutilización, se considera poco conveniente en el caso de inmuebles de valor cultural, simbólico, histórico, estético o documental. En este sentido parece claro que se trata de una práctica proyectual muy extendida pero acotada a espacios básicamente utilitarios, cuya intencionalidad se aleja de los principios de la conservación del denominado patrimonio edifi- 
cado. Por tanto "no debe aceptarse ni tomarse en consideración en materia de Conservación de Bienes Culturales (...) Si entendemos por 'remodelar' el cambiar o dar una nueva forma o volumen envolvente (...) no puede admitirse su aplicación a objetos culturales -sustancialmente históricos y estéticos" (Díaz-Berrio 2002, 45).

El proyecto de reutilización, cuando se trata de remodelar o renovar tiene, por definición, una gran libertad y amplitud en cuanto a modificar y reconfigurar las formas, funciones y apariencia de una construcción o espacio existente. Su motivación se fundamenta en aprovechar y conservar básicamente como soporte a una estructura urbana o arquitectónica existente y cambiar su aspecto y función inicial de manera sustancial, lo cual lo acerca, en cierta medida, al proyecto de nueva creación.

Sin embargo, el proceso de remodelar, renovar e incluso reciclar un espacio preexistente exige un proceso previo de valoración económica, de ubicación y -de creciente importancia hoy día- medioambiental al extender su ciclo de vida útil y evitar procesos de demolición, deshecho y construcción nueva. Por lo tanto, se trata de una alternativa viable y que debe estar en la esfera de la reutilización de un amplio espectro de edificaciones.

Estos conceptos se alinean en buena medida con el denominado "parque inmobiliario" que se refiere a los edificios de poco valor cultural, simbólico o arquitectónico, sobre todo construidos en décadas recientes (30 a 40 años a lo mucho) que no se consideran edificios patrimoniales por las instituciones especializadas. Sin embargo, se trata de un enorme recurso, de un patrimonio de valor económico y social construido a partir de un enorme gasto energético y el uso de recursos materiales, de orden familiar, empresarial o público, que conviene conservar e incrementar su ciclo de vida por razones utilitarias, económicas y por su contribución en la disminución del impacto ambiental que produce la nueva edificación.

\section{EL PROYECTO DE REUTILIZACIÓN ARQUITECTÓNICA, UNA ALTERNATIVA PARA LA CONSERVACIÓN SOSTENIBLE}

Como ya se ha señalado en líneas anteriores, este texto sostiene la premisa importante de que el proyecto de arquitectura que intencionalmente reutiliza espacios arquitectónicos con valor patrimonial contribuye a su conservación y a incrementar su ciclo de vida. En tal sentido se trata de una práctica que atraviesa proyectos que van desde la restauración, hasta la remodelación. La siguiente idea en torno al concepto de la reutilización apunta a una visión holística del término: "La reutilización se visualiza entonces, como un proyecto contemporáneo de arquitectura, que respeta y se apropia de los elementos significativos del lugar, aquellos que le dan precisamente el 'valor' 
que justifica su preservación, pero simultáneamente ha de aportar lo propio como parte del proceso de 'apreciar', 'acumular' y 'transmitir' valor. No se trata entonces de un trabajo de mera conservación del carácter patrimonial de un sitio determinado, sea este orden histórico, estético, ambiental o económico. Incluye estos valores, por supuesto, pero también implica entender e interpretar el entorno donde se actúa tanto en lo físico, como lo inmaterial, en su lógica funcional, formal y tectónica, sin olvidar la importancia de la percepción subjetiva y la significación social en la construcción y uso como nuevo espacio arquitectónico" (Soria y Guerrero 2016, 138).

Conviene destacar que interesa ubicar la reutilización del patrimonio edificado como una práctica de amplio espectro, pero selectiva en cuanto a los valores que pretende conservar y resaltar. Hablar de valor implica una diversidad de posibilidades, entre ellas las de carácter económico o de orden utilitario, hasta las de tipo cultural y simbólico que deben considerarse para cualquier proyecto de diseño.

Corresponde entonces reiterar la importancia del pilar social de la sostenibilidad, pues somos los individuos y grupos de personas, quienes desarrollamos la actividad económica o quienes damos voz a la naturaleza ante su destrucción progresiva. De la percepción, postura y forma de organización que asuma una determinada sociedad, depende su relación con su entorno cultural y natural. Este valor que asignamos a los espacios construidos que habitamos cambia en el tiempo, en función de la propia evolución social.

La reutilización del patrimonio edificado se interesa por espacios preexistentes que ofrezcan valores importantes e interesantes para el proyecto, en especial del orden arquitectónico (espacialidad, composición, funcionalidad, disposición, materialidad) y cultural y simbólico (estética, histórica, afectivos, referenciales), sin dejar de lado posibilidades ambientales y utilitarias. Pero se aleja de la remodelación, reconversión y del reciclaje, campos de mucha actividad profesional actual, pero con otras motivaciones principales y que se enfocan, sobre todo, en el denominado "parque inmobiliario" que representa un enorme recurso edificado que puede y debe aprovecharse al máximo.

Por otro lado, se entiende que la conservación, restauración y rehabilitación de bienes culturales inmuebles constituyen especialidades en sí mismas. De larga tradición, en sus metodologías incorporan el uso y destino actual del inmueble que se ha de preservar. No podría entenderse de otra manera, pues el patrimonio edificado forma parte activa de nuestros espacios de vida.

El siguiente cuadro busca ilustrar y sintetizar las ideas arriba expuestas. No debe tomarse como un esquema inamovible, pues cada caso plantea un problema específico y sus propias soluciones. Incluso los sitios pendientes de 
intervención pueden requerir en muchas ocasiones un acercamiento múltiple, en el que se mezclen o superpongan intencionalidades, soluciones y formas de intervención. Sin embargo, en términos generales, podemos señalar ciertos parámetros encaminados a conservar o transformar la preexistencia a través de un proyecto de diseño arquitectónico que propone un nuevo uso o, en su caso, el mismo uso, pero actualizado, en función de un proceso de valoración del inmueble preexistente.

La conservación del entorno construido, en especial aquel que está considerado como patrimonio por su importancia histórica, cultural, social, económica y, desde luego, ambiental, pasa entonces por su utilización como espacio habitable, capaz de albergar funciones para la sociedad contemporánea, adaptándose a las condiciones actuales -y cada vez más dinámicasde uso, pero simultáneamente, preservando sus características y valores esenciales. Supone un enorme reto, pero el contexto actual demanda soluciones concretas, sensibles y creativas. La reutilización sostenible del patrimonio edificado se convierte en un proceso de diseño e intervención que puede y debe contribuir a preservar y mejorar nuestros espacios de vida como sociedad, contribuir a disminuir el impacto negativo sobre el entorno natural y aportar al desarrollo económico de la comunidad.

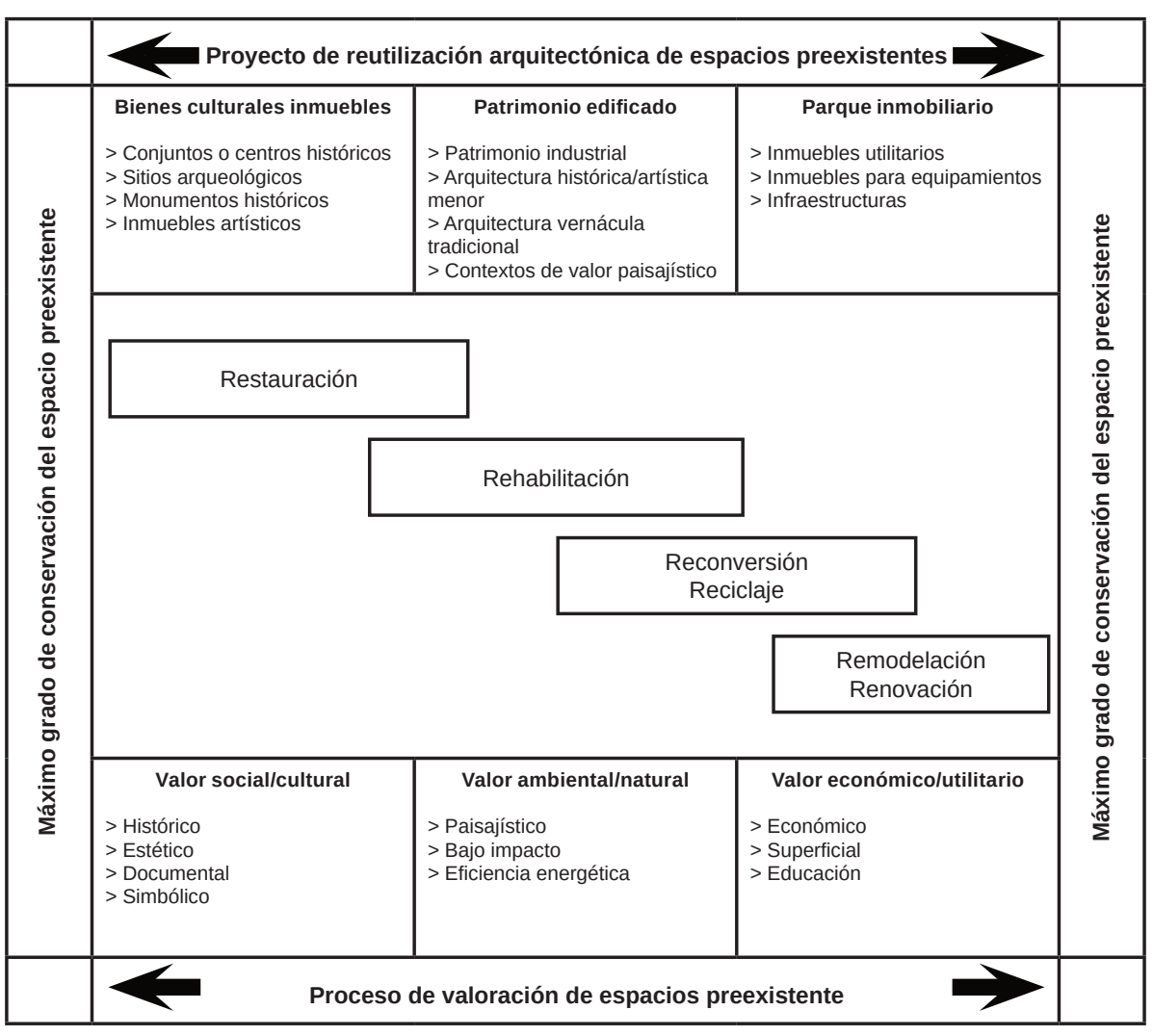




\section{BIBLIOGRAFÍA}

- Barreiro, D. (2012) Arqueología aplicada y patrimonio: memoria y utopía. Complutum, vol. 23, n. ${ }^{\circ}$ 2, pp. 33-50. Disponible en: https://doi.org/10.5209/rev_CMPL.2012.v23. n2.40874 [Consulta: 20/07/2021]

- Capitel, A. (1999) Metamorfosis de monumentos y teorías de la restauración. 2. ${ }^{\text {a }}$ reimp. Madrid: Alianza Editorial

- Choay, F. (2007) Alegoría del Patrimonio. Barcelona: Gustavo Gili

- Díaz-Berrio Fernández, S. (2002) Terminología en materia de conservación del patrimonio cultural. Diseño y Sociedad, n. ${ }^{\circ}$ 13, pp. 40-47. Disponible en: https:// publicaciones.xoc.uam. mx/TablaContenidoFasciculo. php?id_fasciculo=291 [Consulta: 20/07/2021]

- Direction du Patrimoine, Ville d'Arles (2002) Patrimoine en Chantier: l'amphithéâtre. En: Site du Patrimoine d'Arles. Disponibleen: http://www. patrimoine.ville-arles.fr/document/ amphith\%C3\%A9\% C3\%A2tre\%20ar\%C3\%A8nes\% 20Arles\%20patrimoine\%20chantier.pdf [Consulta: 20/ 07/2021]

- Elefante, C. (2007) The Greenest Building Is...One That Is Already Built. Forum Journal, vol. 21, n. ${ }^{\circ} 4$. Disponible en: http://www.ipedconference.com/referencematerials/ Article_The_Greenest_Building_Is_One_That_Is_Already_ Built_by_Cārl_Elefante_AIA_LEED_AP_Forum_Journal_ Summer_2007.pdf [Consulta: 20/07/2021]

- González-Varas, I. (2003) Conservación de bienes culturales. Teoría, historia, principios y normas. Madrid: Cátedra

- Gracia, F. de (2001) Construir en lo construido. La arquitectura como modificación. Hondarribia (Guipúzcoa): Nerea

- ICOMOS (1964) Carta Internacional sobre la Conservación y Restauración de Monumentos y Sitios (Carta de Venecia 1964). II Congreso Internacional de Arquitectos y Técnicos de Monumentos Históricos, Venecia 1964, Adaptada por ICOMOS en 1965. Disponible en: https:// www.icomos.org/charters/veni ce_sp.pdf [Consulta: 20/07/2021]

- Louis, L. (2021) Reconstrucción de Notre Dame crea polémica. Deutsche Welle, 14.04.2021. Disponible en: https://p.dw.com/p/3s1mA [Consulta: 15/05/2021]

- Lucchi, E. (2015) Sostenibilidad y eficiencia energética de los edificios históricos. revista $\mathrm{PH}, \mathrm{n}^{\circ}{ }^{\circ}$ 88. Disponible en: http://www.iaph.es/revistaph/index.php/revistaph/article/ view/3665 [Consulta: 20/07/2021]

- Martínez Monedero, M.(2012)Reciclaje dearquitecturavs restauración arquitectónica, ¿herramientas contrapuestas? Hábitat y Sociedad, n. ${ }^{\circ}$ 5, pp. 23-33. Disponible en: https:// idus.us.es/handle/11441/51920 [Consulta: 20/07/2021]
- Mason, R. y Torre, M. de la (2001) Heritage conservation and values in globalizing societies. En: World culture report 2000: Cultural diversity, conflict and pluralism. Paris: UNESCO, pp. 164-179. Disponible en: https:// unesdoc.unesco.org/ark:/48223/pf0000121058 [Consulta: 22/07/2021]

- Mayorga Trejo, V.A. y Soria López, F.J. (2015) La reutilización urbano-arquitectónica: como alternativa de diseño sustentable. En: Investigación y Diseño. México DF: UAM-X, CyAD, Publicaciones CyADvol, vol. 1. Disponible en: https://publicaciones.xoc.uam.mx/TablaContenidoLibro. php?id_libro=533 [Consulta: 20/07/2021]

- Metropoleruhr (2013) Emscher Landscape Park Visitor's Guide. Regionalverband Ruhr. Essen, 2013. Disponible en: https://shop.rvr.ruhr/media/pdf/a3/3d/a5/ Erlebnisfuehrer_Emscher_Landschaftspark_en_2013.pdf [Consulta: 20/07/2021]

- Naciones Unidas (2015) Transformar nuestro mundo: la Agenda 2030 para el Desarrollo Sostenible. A/RES/70/1. Disponible en: https://unctad.org/system/files/official-document/ ares70d1_es.pdf [Consulta: 20/07/2021]

- Olivares Baró, C (2021) Premio Pritzker 2021: aquí los proyectos de Anne Lacaton y Jean Philippe Vassal. La Razón, ed. México, 16/03/2021. Disponible en: https://www.razon. com.mx/cultura/anne-lacaton-jean-philippe-vassal-ganaronpremio-pritzker-2021-427245 [Consulta: 20/07/2021]

- Real Academia Española [RAE] (2001) Diccionario de la Lengua Española. 22. ${ }^{\mathrm{a}}$ ed. Madrid: ESPASA, vol. II

- Soria López, F.J. (2006) El diálogo ético en el proyecto sostenible. Parque Duisburg-Nord, Alemania. En: Anuario de estudios de arquitectura, historia, crítica, conservación. México D.F.: Universidad Autónoma Metropolitana

- Soria López, F.J. y García Koch, A.B. (2017) La reutilización del patrimonio edificado en el marco del desarrollo sostenible. Diseño en Síntesis, n. ${ }^{\circ}$. 57, año 24, primavera. Disponible en: https://disenoensintesisojs. xoc.uam. mx/index.php/disenoensintesis/article/view/352 [Consulta: 20/07/2021]

- Soria López, F.J. y Guerrero Baca, L.F. (2016) El proyecto de reutilización arquitectónica: hacia una valoración ampliada del patrimonio edificado. Academia XXII, vol. 7 , n. ${ }^{0} 13$, febrero-junio. Disponible en: http://revistas.unam.mx/ index.php/aca/article/view/56314 [Consulta: 20/07/2021] 